\title{
Synthesis of Silver Nanoparticles Using Orange Peel Extract Prepared by Plasmochemical Extraction Method and Degradation of Methylene Blue under Solar Irradiation
}

\author{
Margarita I. Skiba ${ }^{1}{ }^{1}$ and Victoria I. Vorobyova ${ }^{2}$ \\ ${ }^{1}$ Department of Inorganic Materials Technology and Ecology, Ukrainian State University of Chemical Technology, \\ Dnipro 49005, Ukraine \\ ${ }^{2}$ Department of Physical Chemistry, National Technical University of Ukraine "Igor Sikorsky Kyiv Polytechnic Institute", \\ Kyiv 03056, Ukraine
}

Correspondence should be addressed to Margarita I. Skiba; margaritaskiba88@gmail.com

Received 27 July 2019; Accepted 30 August 2019; Published 9 October 2019

Academic Editor: Luigi Nicolais

Copyright (c) 2019 Margarita I. Skiba and Victoria I. Vorobyova. This is an open access article distributed under the Creative Commons Attribution License, which permits unrestricted use, distribution, and reproduction in any medium, provided the original work is properly cited.

\begin{abstract}
In pursuit of greener nanoscale research, the utilization of the reductive potency of a common byproduct of food-processing industry, i.e., orange peel, has been researched to prepare "green" silver nanoparticles (AgNPs). The synthesized AgNPs were characterized by UV-Vis spectroscopy, dynamic light scattering, and scanning electron microscopy. The results confirmed that silver nanoparticles were formed at the investigated concentrations of $\mathrm{Ag}^{+}(0.25-6.0 \mathrm{mmol} / \mathrm{L})$ during $5-10$ minutes, at ratio $\mathrm{AgNO}_{3}$ : extract $(\mathrm{mL})=1: 1$, and at $75^{\circ} \mathrm{C}$. From the SEM images, the silver nanoparticles are found to be almost spherical. Powder $\mathrm{XRD}$ results reveal that Ag nanoparticles had a face-centered cubic crystal structure. The zeta potential value for AgNPs obtained was $-21.7 \mathrm{mV}$, indicating the moderate stability of synthesized nanoparticles. The effect of $\mathrm{pH}$ on nanoparticle synthesis has been determined by adjusting the $\mathrm{pH}$ of the reaction mixtures. The catalytic effectiveness of the prepared green catalyst, AgNPs, has also been investigated in catalytic degradation of methylene blue (MB) dye. The catalytic degradation reaction under solar irradiation was completed (99\%) within $35 \mathrm{~min}$, signifying excellent catalytic properties of silver nanoparticles in the reduction of MB.
\end{abstract}

\section{Introduction}

Nowadays, green chemistry is an emphasized area of research and requires some additional efforts for the implementation of sustainable methods in order to achieve the desired products as well as minimize and further eliminate the waste materials produced. Metal nanoparticles (NPs) have received significant interest in the area of scientific research and industrial applications [1]. Silver (Ag) NPs have generated substantial demand not only in fundamental research and development but also at the industrial scale due to their excellent properties [2]. Different traditional methods have been employed in the production of nanosized metallic silver particles with different morphologies and sizes, for example, chemical reduction, electrochemical, photochemical, microwave-assisted, hydrothermal, laser ablation, and sol-gel methods [3-6]. As these methods utilize precarious and environmentally lethal chemicals and require high energy or low material conversions as well as tedious purification, different issues arise while going through these processes, mainly regarding stabilization and aggregation of nanoparticles. There is a need to develop new methods of synthesizing nanoparticles that are less costly, energy efficient, and use nontoxic, environment-friendly renewable resources such as phytochemicals extracted from plants. This would definitely mean applying the "green chemistry" principles $[7,8]$. Green chemistry is the utilization of a set of principles that will help reduce the use and generation of hazardous substances during the manufacture and application of chemical products. Green chemistry aims to protect the environment not by cleaning up but by inventing new chemical processes that do not pollute. It is a rapidly 
developing and important area in the chemical sciences. Recently, as a further step towards the development of greener and more sustainable processes, attempts have been made to replace plant parts with agroindustrial wastes [9]. Overall, the use of agroindustrial wastes for the eco-friendly production of nanoparticles seems to be promising, but relatively few studies conducted on this topic make it difficult to draw definitive conclusions [10].

Orange is one of the world's largest fruit crop with a global production of $48.8(2016 / 17)$ million tons [11]. A large portion of this production is used for the industrial extraction of citrus juice, which leads to vast amounts of residues, including peel and segment membranes. Peels represent between 50 and $65 \%$ of the total weight of the fruits and remain as the primary byproduct. This biomass is rich in bioflavonoids, insoluble and soluble fibers, as well as proteins, all of which have potential applications in nanobiotechnology, such as in the synthesis of nanoparticles $[12,13]$.

However, an analysis of the pertinent literature revealed actual issues and shortcomings limiting the advancement of green synthesis [1-13]. Significant issues have been associated with the source/type and concentration of plant extracts and waste materials. The formation of NPs using plant extracts, as a rule, proceeds in two stages: preparation of the extract and its subsequent use as a reducing/stabilizing agent. Up to now, several conventional extraction techniques have been reported for the extraction of phenols from citrus peels like solvent extraction, hot water extraction, alkaline extraction, resin-based extraction, and electron beam- and c-irradiation-based extractions. Different extraction techniques have been studied in an effort to increase the yield, including ultrasound-assisted extraction from biomaterials, superheated liquid extraction, or fluidized-bed extraction, between others [14-16]. These conventional or more innovative extraction techniques may either cause the degradation of the targeted compounds due to high temperature and long extraction times as in solvent extractions or pose some health-related risks due to the unawareness of safety criteria during irradiation. The newest method of processing homogeneous and heterogeneous systems, including plant material, is plasma discharges of various configurations $[17,18]$. Among plasmochemical discharges, the contact nonequilibrium low-temperature plasma (CNP) is a promising option from the point of view of practical applications. Plasma discharge is generated between the electrode in a gaseous phase and a liquid surface, where another electrode is located [19]. Therefore, chemical transformations on the phase boundary are conditioned by the combined effect of the electrochemical oxidation-reduction, initiated photolysis reactions, UV radiation, and a flow of charged particles from the gaseous phase to the surface of the liquid medium. These factors may increase the extraction efficiency and concentration of the resulted extracts, and, as a consequence, the efficiency of further synthesis of AgNPs.

The main goal is to determine the synthesis conditions for green-synthesis silver nanoparticles with the use of the orange peel extract prepared by the plasmochemical extraction method and investigate the decolorization of the representative cationic phenothiazine dye in the presence of nanocatalysts.

\section{Materials and Methods}

2.1. Materials. Silver nitrate (99.8\%, Kishida), potassium ferricyanide, methylene blue (MB), ascorbic acid, butylated hydroxytoluene, and phosphate buffer were used. Aqueous solutions of the precursor were prepared using ultrapure water (Direct-Q UV, Millipore) and were utilized as starting materials without further purification.

2.2. Preparation of Orange Peel Water Extract. Orange peel (OrP) was stored in plastic bags at $4^{\circ} \mathrm{C}$ until treatment. The orange peel was dried at $100^{\circ} \mathrm{C}$ for $48 \mathrm{~h}$ and grounded to obtain a fine powder. The bidistilled water $(40 \mathrm{ml})$ was added to $1 \mathrm{~g}$ of dry OP powder and stirred. The resulting mixture was placed in a plasmochemical reactor (Figure 1). The scheme and the principle of the plant operation for the plasmochemical reactor are given in [20-22]. The mixture was treated with CNP discharge for 5 minutes (at the amperage of $I=120 \mathrm{~mA}$ and $P=0.8 \mathrm{MPa}$ ), cooled, and filtered. The freshly obtained OrP water extract was used immediately after filtration. Furthermore, such extracts are mentioned as the chemically derived orange peel water extracts (PC OrPWE). As a control sample, an aqueous extract obtained by traditional methods (T OrPWE) was used. The conventional grape pomace extract was obtained by boiling $1 \mathrm{~g}$ of grape pomace powder with $40 \mathrm{ml}$ for $15 \mathrm{~min}$, followed by cooling and filtration. The freshly prepared extracts were used for further experiments.

2.3. Synthesis of Silver Nanoparticles (AgNPs) with Orange Peel Water Extract. $\mathrm{AgNO}_{3}$ was dissolved in bidistilled water to prepare the solutions with concentrations in the range $0.25-6.0 \mathrm{mmol} / \mathrm{L}$. In a typical reaction procedure, $40 \mathrm{ml}$ of the orange peel extract was added to $40 \mathrm{ml} \mathrm{AgNO}_{3}$ solution under stirring during $0.1 \mathrm{~min}$. The final product was colloidal dispersion. The obtained mixture was heated at $75^{\circ} \mathrm{C}$ for an appropriate time. The color change of the mixture of " $\mathrm{AgNO}_{3}-\mathrm{PC}$ OrPWE" to brown indicates the formation of AgNPs. The strong SPR band at $400-450 \mathrm{~nm}$ in UV-Vis spectra additionally confirms the formation of the AgNPs [1-5, 23-25]. The AgNPs obtained by chemical synthesis were centrifuged at $5000 \mathrm{rpm}$ for $5 \mathrm{~min}$. The dried powders were used for further characterization. The $\mathrm{pH}$ was adjusted by using $0.1 \mathrm{~N} \mathrm{NaOH}$ and $0.1 \mathrm{~N} \mathrm{HCl}$.

2.4. Synthesis of Silver Nanoparticles (AgNPs) with Grape Pomace Extract. Synthesised $\mathrm{AgNO}_{3}$ was dissolved in bidistilled water to prepare solutions with concentrations in the range $0.25-6.0 \mathrm{mmol} / \mathrm{L}$. In a typical reaction procedure, $40 \mathrm{ml}$ of grape pomace extract was added to $40 \mathrm{ml} \mathrm{AgNO}_{3}$ solution under stirring during $0.1 \mathrm{~min}$. The final product was colloidal dispersion. A $250 \mathrm{~mL}$ conical flask was then placed in a water bath at a temperature of $75^{\circ} \mathrm{C}$. The temperature of 


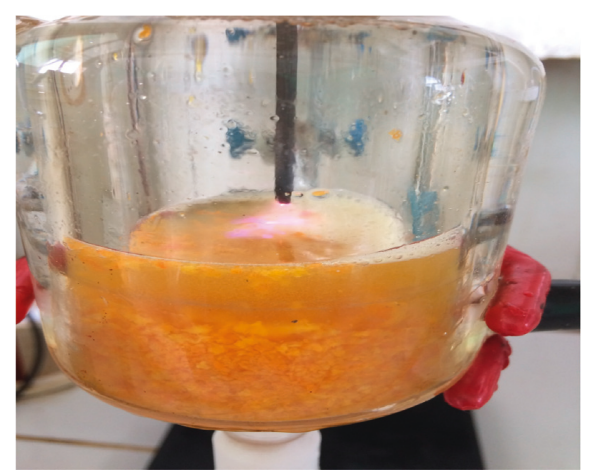

(a)

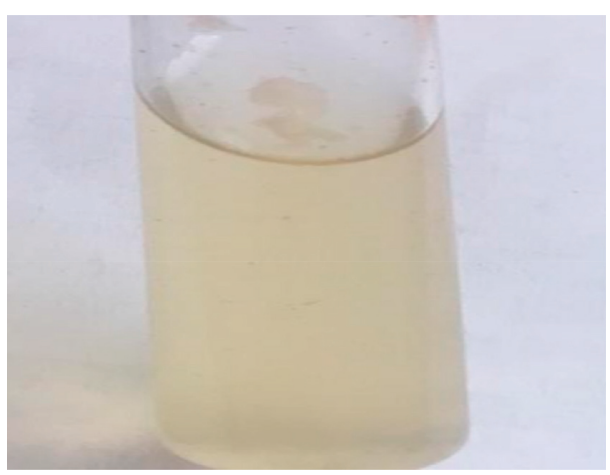

(b)

Figure 1: Plasmochemical treatment of dry orange peel powder (a) and plasmochemically obtained grape pomace water extract after filtration (b).

the reaction mixture was maintained at $75^{\circ} \mathrm{C}$ for fixed times in a water bath. The reaction mixture was removed from the water bath and allowed to cool to room temperature $\left(25^{\circ} \mathrm{C}\right)$. The color change of the " $\mathrm{AgNO}_{3}-\mathrm{PC}$ OrWE" mixture to brown indicates the formation of AgNPs. The strong SPR band at $400-450 \mathrm{~nm}$ in UV-Vis spectra additionally confirms the formation of AgNPs. The AgNPs obtained by chemical synthesis were centrifuged at $5000 \mathrm{rpm}$ for $5 \mathrm{~min}$. The dried powders were used for further characterization.

2.5. Determination of Reducing Power. Fe(III) reduction is often used as an indicator of electron-donating activity, which corresponds to the phenolic antioxidant effect [23]. Extracts, which have a reduction potential, react with potassium ferricyanide $\left(\mathrm{Fe}^{3+}\right)$ to form potassium ferrocyanide $\left(\mathrm{Fe}^{2+}\right)$, which then reacts with ferric chloride to form a ferrous complex. Such complex has an absorption maximum at $\lambda=700 \mathrm{~nm}$. To prepare the reaction solution, a different amount of the extract, after the rotary evaporator, was mixed $(0.005 \mathrm{~g}, 0.01 \mathrm{~g}, 0.015 \mathrm{~g}, 0.02 \mathrm{~g}$, and $0.025 \mathrm{~g})$ with an appropriate amount of solvent $(1 \mathrm{~mL}), 1 \mathrm{~mL}$ phosphate buffer (0.2 M, pH 6.6), and $1 \mathrm{ml}$ of potassium ferricyanide solution (1\%). The resulting mixture was incubated at $50^{\circ} \mathrm{C}$ for 20 minutes. To terminate the reaction, $1 \mathrm{~mL}$ of trichloroacetic acid (10\%) was added to the mixture. The obtained solution was cooled for 5 minutes and centrifuged at $3000 \mathrm{rpm}$ for 10 minutes. From the top layer of each solution, $2 \mathrm{ml}$ of aliquots were taken and mixed with $2 \mathrm{~mL}$ of distilled water and $0.4 \mathrm{~mL}$ of ferric chloride solution $(0.1 \%)$. The absorbance value of solutions was measured at $700 \mathrm{~nm}$. Increasing absorbance of the reaction mixture indicates increasing reducing power. Results were expressed as mean \pm standard deviation (SD) of 5 replicate measurements, with the ascorbic acid as a reference reducing agent.

2.6. Characterization Techniques. Spectra of colloidal solutions were obtained using the spectrophotometer UV$5800 \mathrm{PC}$ and quartz cuvettes in the wavelength range of $\lambda=190-700 \mathrm{~nm}$ (FRU, China). Particle size was determined by the particle size analyzer Zetasizer Nano-25 (Malvern Instruments Ltd., Malvern, England). Microphotographs of nanoparticles were obtained on a scanning electron microscope JEOL JSM-6510LV (JEOL, Tokyo, Japan). The disperse phase of the solution obtained as a result of plasmochemical treatment of the solution and air-dried at $25^{\circ} \mathrm{C}$ was studied with the use of X-ray diffractometer Ultima IV Rigaku. In addition, the presence of metals in the sample was analyzed by energy-dispersive spectroscopy (EDS).

2.7. Catalytic Degradation. In a typical assay, $10 \mathrm{~mL}$ of $10 \mathrm{mM}$ stock solution of $\mathrm{MB}$ was mixed with $3 \mathrm{~mL}$ of $1 \mathrm{mM}$ freshly prepared $\mathrm{NaBH}_{4}$ solution. Three different samples were prepared. One blank sample was prepared without AgNPs. In the second sample, $0.05 \mathrm{~mL}$ of as-synthesized colloidal AgNPs was further added into the previously made mixture of $\mathrm{MB}$ and $\mathrm{NaBH}_{4}$. The final volume of the reaction mixture in all three samples was adjusted to $16 \mathrm{~mL}$ by adding $\mathrm{ddH}_{2} \mathrm{O}$. The experiment was carried out at ambient temperature. The evaluation of catalytic decomposition process was calculated by the differentiation of optical absorption spectra of methylene blue. The solar light degradation of $\mathrm{MB}$ was observed in certain time intervals and by analyzing the reduction in the intensity of $\mathrm{MB}$ at a maximum absorption peak of $663 \mathrm{~nm}$ using a UV-Vis spectrophotometer.

\section{Results and Discussion}

AgNPs were synthesized using plasmochemically obtained orange peel extract mixed with silver nitrate solution (OrPWE-AgNPs) (Figure 2). The yellow extract started changing and ultimately turned to a dark brown extract after $\sim 10$ min (Figure 2(a)). The presence of an absorption peak at $430 \mathrm{~nm}$ on the presented curve indicates the Ag nanoparticles formation after reaction with plasmochemically obtained OrPWE (Figure 2(a)). The reaction was monitored by UV-Vis spectroscopy over the course of $20 \mathrm{~min}$ in order to study the kinetics of the reaction (Figure 2(b)). It was established that a gradual increase in the absorbance is observed during the first 1-10 min of synthesis, which indicates the rise of the AgNPs content with the growth of treatment duration.

Figure 3 shows the UV-Vis absorption spectra of AgNPs obtained at different concentrations of $\mathrm{AgNO}_{3}$ (0.25- 


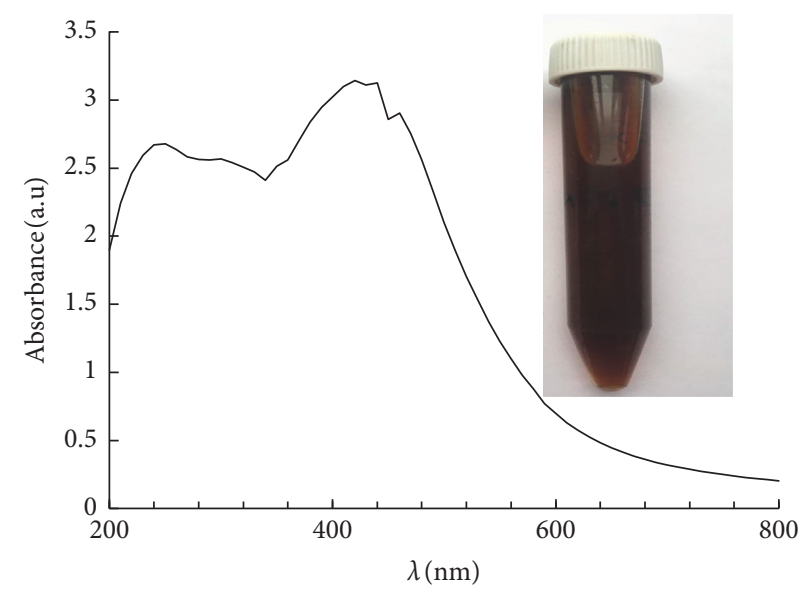

(a)

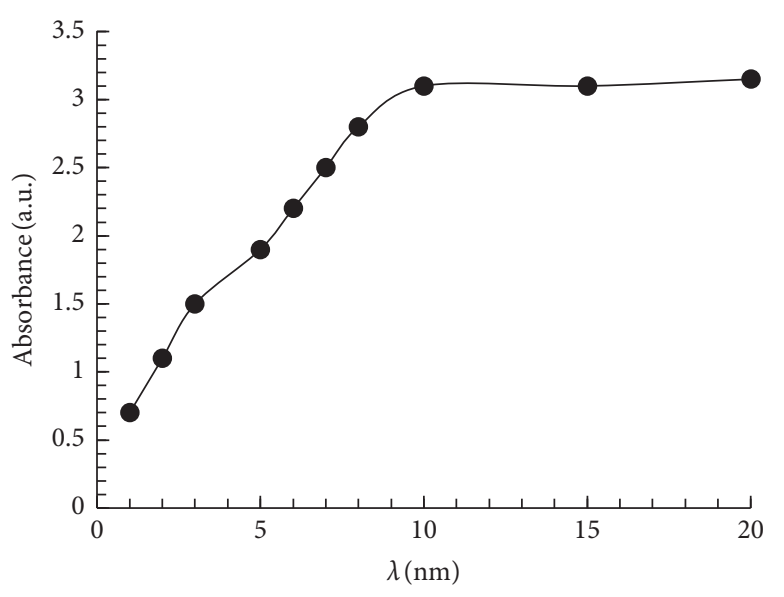

(b)

Figure 2: UV-Vis absorption spectrum of OrPWE-AgNPs after $10 \mathrm{~min}$ of reaction displaying the characteristic surface plasmon resonance band at $430 \mathrm{~nm}$ (a). The kinetic progression of the OrPWE-AgNPs reaction during $20 \mathrm{~min}$ with the absorbance at $430 \mathrm{~nm}$ (b).

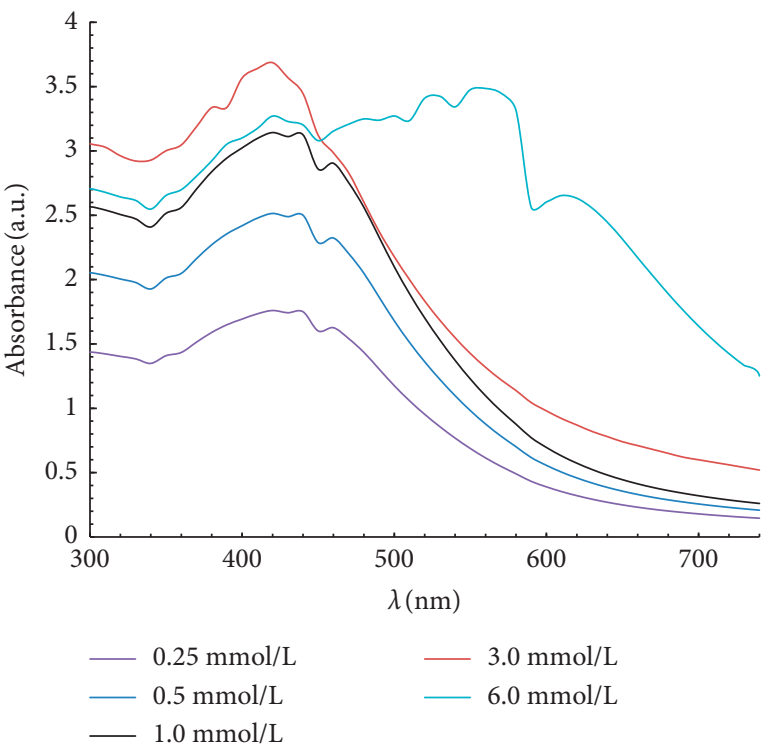

FIGURE 3: Absorption spectra of obtained colloidal solutions of silver nanoparticles using plasmochemically obtained OrPWE and $\mathrm{Ag}^{+}$concentrations $(1-0.25 \mathrm{mmol} / \mathrm{L}, 2-0.5 \mathrm{mmol} / \mathrm{L}, 3-1.0 \mathrm{mmol} / \mathrm{L}$, $4-3.0 \mathrm{mmol} / \mathrm{L}$, and $5-6.0 \mathrm{mmol} / \mathrm{L}$ ).

$6.00 \mathrm{mmol} / \mathrm{L}$ ) and in the presence of fixed amount of plasmochemically obtained aqueous extract (AgNPs synthesized at $75^{\circ} \mathrm{C}, \tau=10$ minutes, and ratio $\mathrm{AgNO}_{3}$ : extract $(\mathrm{mL})=1: 1)$. As it can be seen, as the concentration of silver nitrate changes from 0.25 to $0.5 \mathrm{mmol} / \mathrm{L}$, the intensity of the surface plasmon resonance (SPR) peak increases remarkably and the location of SPR peak. The increase in intensity suggests that more nanoparticles are formed [1-14, 26-28]. Thus, it can be assumed that although the silver nitrate concentration has increased, the particle size has not increased much. However, while the concentration of silver nitrate has altered from $1.0 \mathrm{mmol} / \mathrm{L}$ to $3.0 \mathrm{mmol} / \mathrm{L}$, the intensity of the SPR peak has increased slightly. The slight increase of SPR intensity may occur due to exhaustion of the

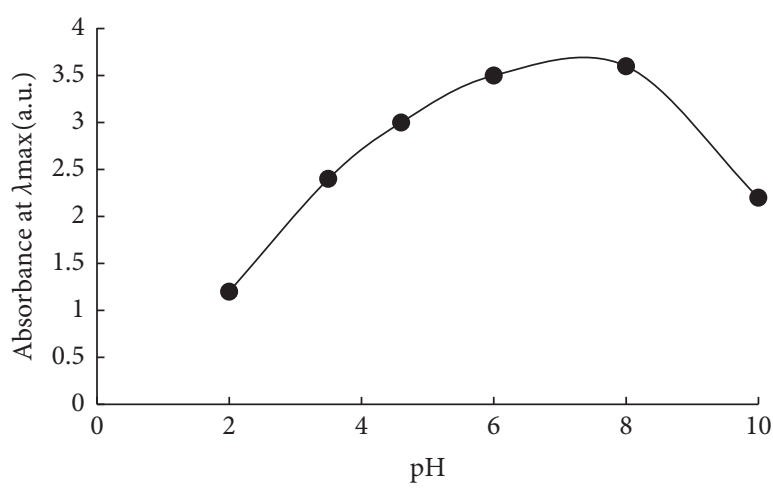

Figure 4: The effect of $\mathrm{pH}$ on the formation of AgNPs using plasmochemically obtained OrPWE $\left(\mathrm{C} \quad\left(\mathrm{Ag}^{+}\right)=1.0 \mathrm{mmol} / \mathrm{L}\right.$, $\tau=10 \mathrm{~min}$, and ratio $\mathrm{AgNO}_{3}$ : extract $\left.(\mathrm{mL})=1: 1\right)$.

reducing agent. With an increase in the concentration of silver ions to $6.0 \mathrm{mmol} / \mathrm{L}$, the intensity of the peak slightly increases and there are obvious pairs of absorption peaks at $424 \mathrm{~nm}$ and $530 \mathrm{~nm}$, which indicates that aggregation occurs in this reactive system and the nanoparticles are well dispersed.

The effect of $\mathrm{pH}$ on the formation of AgNPs has been evaluated by UV-Visible spectroscopic studies and is given in Figure 4. From the figure, it is evident that the formation of AgNPs mainly depends on the $\mathrm{pH}$ of the reaction medium. The absorbance value has increased gradually with increasing $\mathrm{pH}$ range from 2 to 10 (4.7 initial $\mathrm{pH}$ ), suggesting that the rate of formation of AgNPs is higher in basic $\mathrm{pH}$ than in acidic $\mathrm{pH}$. The formation of AgNPs occurs rapidly in neutral $\mathrm{pH}$, and in the basic $\mathrm{pH}$, it may be due to the ionization of the phenolic group present in the extract [29-31]. The slow rate of formation and aggregation of AgNPs at acidic $\mathrm{pH}$ could be related to electrostatic repulsion of anions present in the solution.

The main characteristics of silver nanoparticles in the dispersed system were investigated, namely, the average size and morphology, polydispersity, and stability of nanoparticles. 
The size distributions of the nanoparticles were first determined by dynamic light scattering (DLS) (see Table 1). For OrPWE-AgNPs, DLS analysis showed nanoparticles with an average hydrodynamic diameter of $47-63 \mathrm{~nm}$, with a polydispersity (PDI) of $0.26-0.78$.

From the data obtained (Table 1), it can be seen that with the increasing initial concentration of argentium ions in solution from 0.25 to $3.0 \mathrm{mmol} \cdot \mathrm{l}^{-1}$, the average size of nanoparticles increases from $47 \mathrm{~nm}$ to $53 \mathrm{~nm}$, which is not significant. At the same time, the dispersion field index also increases in a small range. The PDI value " 0 " represents monodisperse distribution, whereas the value " 1 " represents polydisperse distribution.

This indicates that the nanoparticles formed have a slight size difference. At an initial concentration of $6.0 \mathrm{mmol} \mathrm{L}^{-1}$, the average particle size was $63 \mathrm{~nm}$ and the polydispersity index doubled. These data are consistent with the results presented in Figure 3 where the absorption band has shifted to the infrared side. It is likely that the amount of stabilizing agents in the extract at $\mathrm{C} \mathrm{Ag}^{+} 6 \mathrm{mmol} \mathrm{L}^{-1}$ is not sufficient, which leads to the formation of larger particles and a wide size difference (as evidenced by the dispersion field index).

The zeta potential of dispersion refers to the electrostatic voltage at the shear layer of a nanoparticle. In this AgNPs system, the zeta potential for Or-AgNPs was $-21.7 \pm 0.4 \mathrm{mV}$. Usually, a colloid system would be considered electrostatically stable when its zeta potential values are above $+30 \mathrm{mV}$ or below $-30 \mathrm{mV}$. In this case, the dispersion was stable for over 1-2 months as the stabilization involved not only electrostatic interactions but also steric hindrance provided by biomolecules that interacted with the nanoparticles acting as physical barriers that avoid the coalescence and aggregation of the nanoparticles. The stability of nanoparticles was determined by keeping the purified nanoparticles solution at room temperature for different day intervals.

Surface morphology of synthesized nanoparticles was examined by scanning electron microscopy (SEM). The AgNPs were also analyzed under the scanning microscope (Figure 5). The sample $\left(\mathrm{C}\left(\mathrm{Ag}^{+}\right)=1.0 \mathrm{mmol} / \mathrm{L}, \tau=10 \mathrm{~min}\right.$, and ratio $\mathrm{AgNO}_{3}$ : extract $\left.(\mathrm{mL})=1: 1\right)$ has been investigated (Figure 5). SEM images show the particles are uniformly spherical in shape. This corresponds with the data presented in Table 1. The average sizes of the particles were around $50.0 \mathrm{~nm}$ for orange extract-mediated silver nanoparticle synthesis, and it can also be observed that larger particles of AgNPs are formed due to aggregation of nanoparticles during sample preparation.

The crystalline structure of AgNPs has been confirmed using the analytical technique of X-ray diffraction. The recorded XRD spectrum showed four distinct and wellcharacterized intense diffraction peaks at scattering angles (2) of $37.5^{\circ}, 44.6^{\circ}, 64.44^{\circ}$, and $76.45^{\circ}$, respectively, corresponding to (111), (200), (220), and (311) sets of lattice planes of the face-centered cubic (fcc) structure of metallic silver (Figure 6). The peaks showed that the main composition of nanoparticles was silver, and no other obvious peaks as impurities were found in the XRD patterns.

Finally, we conducted energy-dispersive X-ray spectroscopy (EDX) to illustrate the elemental composition of the metal nanoparticles that were synthesized (Figure 7). The
TABle 1: The particle size and polydispersity index of obtained silver nanoparticles.

\begin{tabular}{lcc}
\hline $\begin{array}{l}\mathrm{C} \mathrm{AgNO}_{3} \\
(\mathrm{mmol} / \mathrm{L})\end{array}$ & $\begin{array}{c}\text { Average particle-sized } \\
\text { AgNPs }(\mathrm{nm})\end{array}$ & Polydispersity index \\
\hline 0.25 & 47.0 & 0.26 \\
0.5 & 48.6 & 0.25 \\
1.0 & 50.0 & 0.27 \\
3.0 & 53.1 & 0.33 \\
6.0 & 63.0 & 0.78 \\
\hline
\end{tabular}

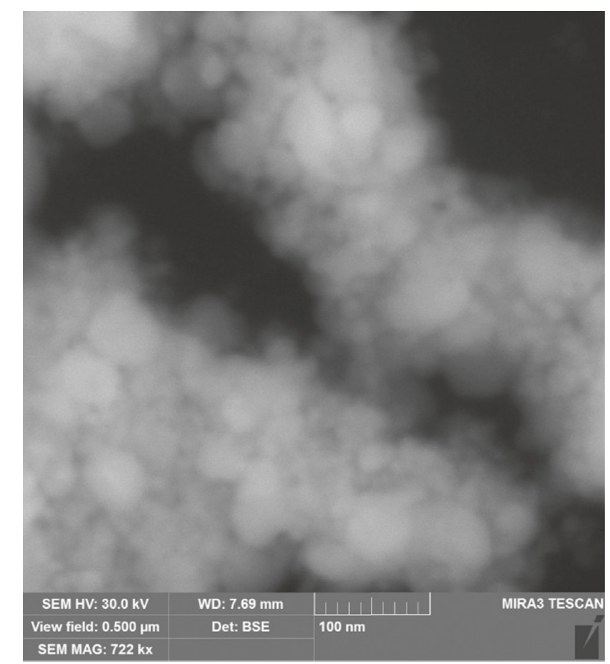

(a)

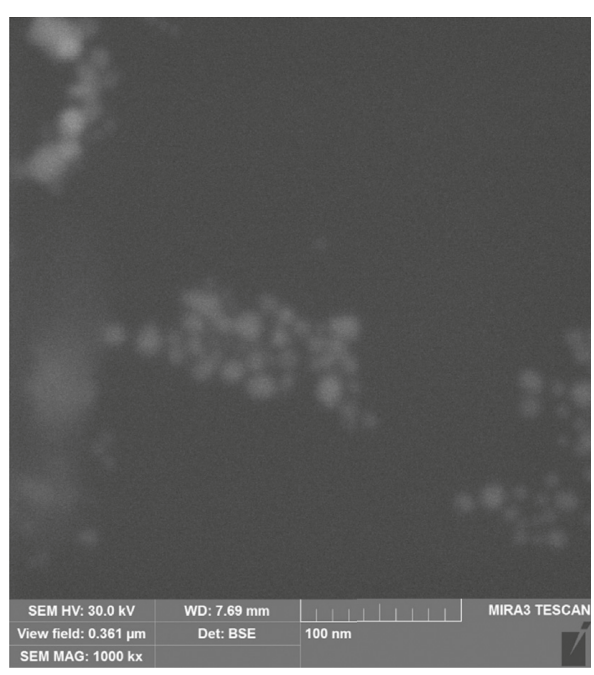

(b)

FIGURE 5: SEM images of obtained silver nanoparticles $\left(\mathrm{C}\left(\mathrm{Ag}^{+}\right)=\right.$ $1.0 \mathrm{mmol} / \mathrm{L}, \tau=10 \mathrm{~min}$, and ratio $\mathrm{AgNO}_{3}$ : extract $\left.(\mathrm{mL})=1: 1\right)$.

synthesized silver nanoparticles produce a strong signal at $3 \mathrm{keV}$, which reveals the presence of silver nanoparticles $[29,32]$. The EDS spectrum analysis also revealed that the AgNPs are in the metallic form with no formation of $\mathrm{Ag}_{2} \mathrm{O}$ in them and free from any other impurities.

It is known that the "green" synthesis of nanoparticles is based on the use of reducing agents present in the composition of biomaterials [7-13]. These substances are characterized by their redox potential and are able to recover 


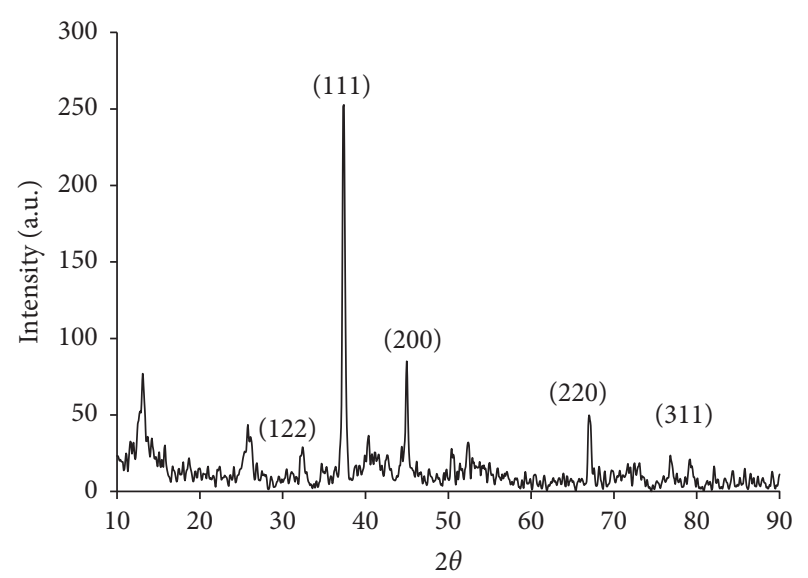

FIgURE 6: X-ray diffraction of obtained silver nanoparticles $\left(\mathrm{C}\left(\mathrm{Ag}^{+}\right)=\right.$ $1.0 \mathrm{mmol} / \mathrm{L}, \tau=10 \mathrm{~min}$, and ratio $\mathrm{AgNO}_{3}$ : extract $\left.(\mathrm{mL})=1: 1\right)$.

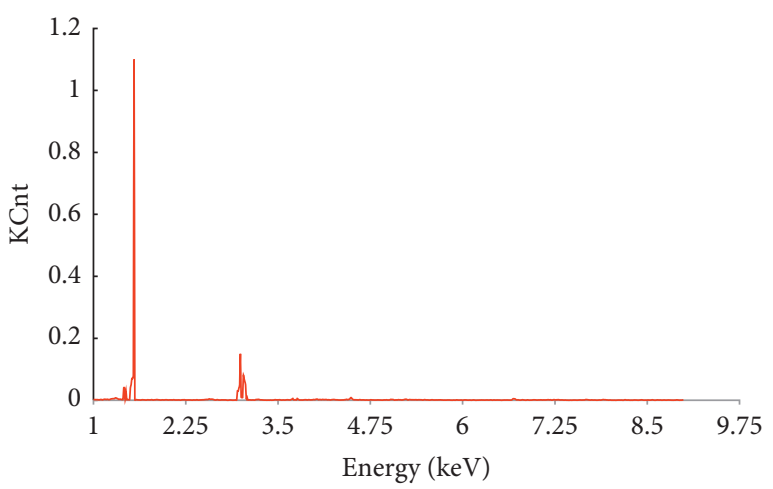

FIGURE 7: EDX spectra of obtained silver nanoparticles $\left(\mathrm{C}\left(\mathrm{Ag}^{+}\right)=\right.$ $1.0 \mathrm{mmol} / \mathrm{L}, \tau=10 \mathrm{~min}$, and ratio $\mathrm{AgNO}_{3}$ : extract $\left.(\mathrm{mL})=1: 1\right)$.

cations of the dissociated metal salts. In addition, they can simultaneously act as stabilizers of the obtained NPs. Taking this into account, the reducing power of aqueous OrP extract obtained under the action of a plasma discharge and by the traditional method was determined. The ferric reducing power of the OrP extracts was examined using the potassium ferricyanide-ferric chloride method (Figure 8).

Higher absorbance of the reaction mixture indicates higher reduction potential. The reducing power of the extracts increases with the rise of their concentrations. Figure 8 shows the concentration-absorbance dependence on the reducing powers of the two different types of water extracts. The highest reducing power, in comparison with the known powerful reducing agents such as ascorbic acid and butylated hydroxytoluene (BHT), has the PC OrPWE.

The catalytic ability of as-synthesized AgNPs was investigated using the reduction reaction of $\mathrm{MB}$ by $\mathrm{NaBH}_{4}$ under the solar light as a model reaction [32-34]. The UVVis absorption spectrum of an aqueous solution of methylene blue shows peaks at 290 and $664 \mathrm{~nm}$ with a hump at $612 \mathrm{~nm}$ due to $\pi \longrightarrow \pi^{*}$ and $n \longrightarrow \pi^{*}$ transitions. The reduction of methylene blue into its colorless form can be followed spectrophotometrically by monitoring the absorption maximum at $664 \mathrm{~nm}$. Figure 9 shows the UV-Vis spectra of $\mathrm{MB}$ reduction by $\mathrm{NaBH}_{4}$ in the presence of a fixed

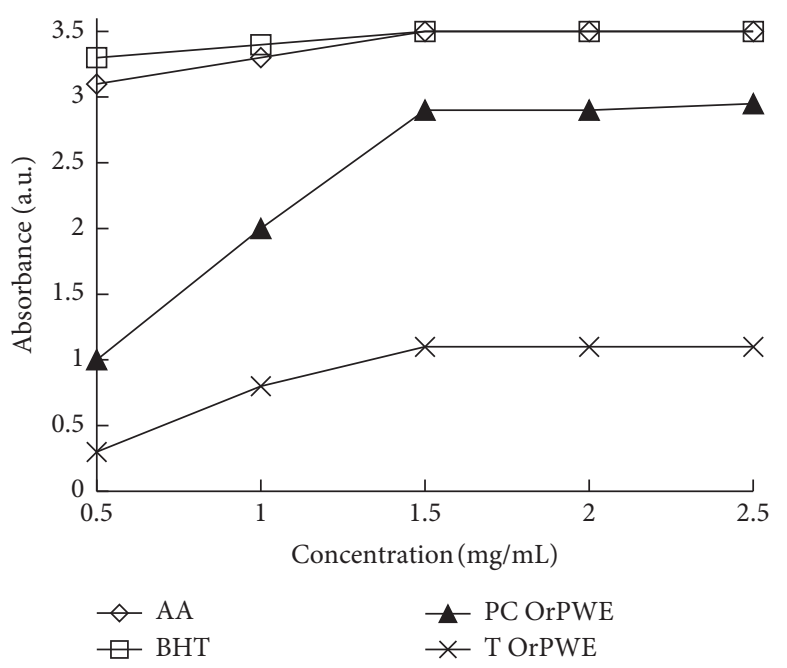

FIGURE 8: Reducing power of OrPWE in comparison with ascorbic acid and BHT.

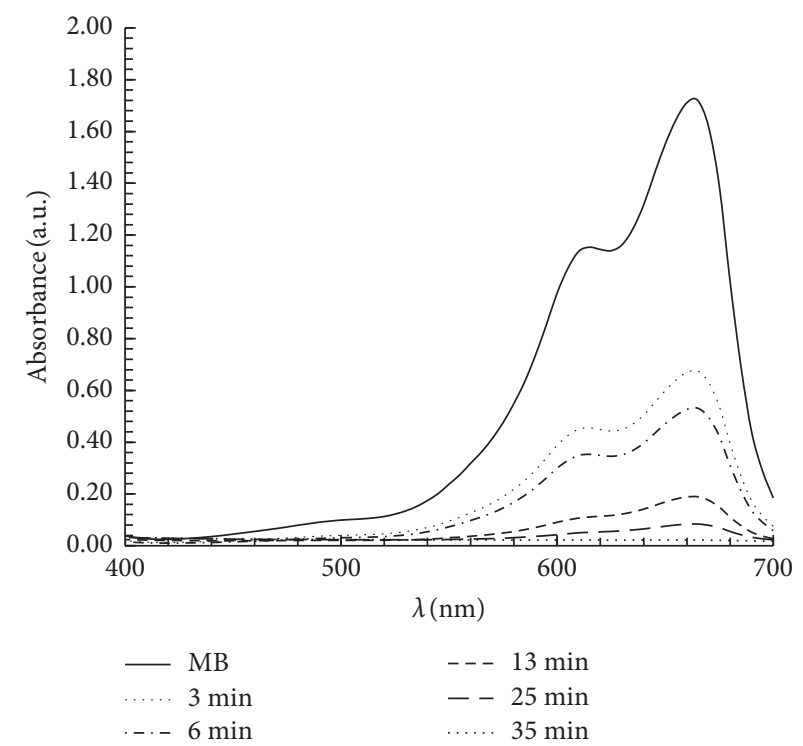

FIgURE 9: UV-Vis absorption spectra for the degradation of methylene blue by $\mathrm{NaBH}_{4}$ in the presence of $0.05 \mathrm{~mL}$ of AgNPs under solar light.

amount of the as-synthesized catalyst, i.e., $0.05 \mathrm{~mL}$. As the control, absorption spectra of degradation of $\mathrm{MB}$ solution without the nanocatalyst were measured at the same condition under the solar light at the same time at the maximum absorption peak around $664 \mathrm{~nm}$ wavelength using the UVVis spectrophotometer. The blank experiments conducted without adding the nanocatalyst have shown no change in color as well as the intensity of $\lambda_{\max }$ at $664 \mathrm{~nm}$. MB is not degraded by $\mathrm{NaBH}_{4}$ alone in the absence of the nanocatalyst. The main absorption peak at $660 \mathrm{~nm}$ decreased gradually with the extension of the exposure time 3-35 min, indicating the photocatalytic degradation of methylene blue dye.

Plot of Ln $\left(A_{\mathrm{t}} / A_{0}\right)$ vs time for catalytic degradation of methylene blue by AgNPs is depicted in Figure 10, and the calculated degradation rate constant value of methylene blue is $0.136 \mathrm{~min}^{-1}$. 


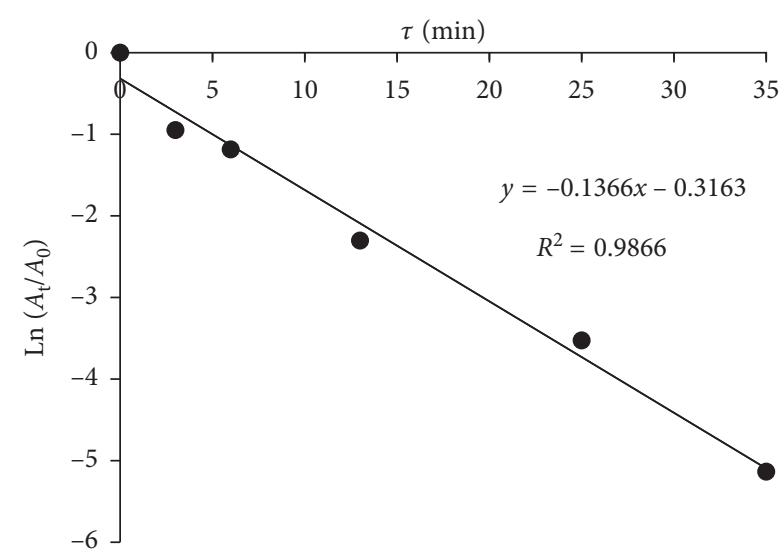

FIgURE 10: Plot of $\operatorname{Ln}\left(A_{\mathrm{t}} / A_{0}\right)$ against time for the degradation of methylene blue using $0.05 \mathrm{~mL}$ of AgNP.

\section{Conclusions}

Green nanotechnology is gaining importance due to the elimination of harmful reagents and provides an effective synthesis of expected products in an economical manner. The results demonstrated that synthesis provides the formation of silver nanoparticles for investigated concentrations of $\mathrm{Ag}^{+}(0.25-6.0 \mathrm{mmol} / \mathrm{L})$ during 5-10 minutes, ratio $\mathrm{AgNO}_{3}$ : extract $(\mathrm{mL})=1: 1$, at $75^{\circ} \mathrm{C}$. From the SEM images, the silver nanoparticles are found to be almost spherical. Powder XRD results revealed that Ag nanoparticles had a face-centered cubic crystal structure. The photocatalytic activity of green-synthesized silver nanoparticles was evaluated by choosing methylene blue dye. The main absorption peak at $660 \mathrm{~nm}$ decreased gradually with the extension of the exposure time, indicating the photocatalytic degradation of methylene blue dye. The MB dye completely degraded within $35 \mathrm{~min}$. The present study has found that the use of a natural, renewable, and ecofriendly reducing agent used for the synthesis of silver nanoparticles exhibits an excellent photocatalytic activity against dye molecules and can be used in water purification systems and dye effluent treatment.

\section{Data Availability}

All data (XRD patterns, EDS spectra, and SEM images) supporting the findings of this study are available within the article and are available from the corresponding author upon reasonable request.

\section{Conflicts of Interest}

The authors declare that they have no conflicts of interest.

\section{Acknowledgments}

This work was supported by a grant from the Ministry of Education and Science of Ukraine (grant no. 2044, 2019-2021) and Program European Union (Harmonising Water-Related Graduate Education/WaterH (http://www.waterh.net)).

\section{References}

[1] O. Hess, J. B. Pendry, S. A. Maier, R. F. Oulton, J. M. Hamm, and K. L. Tsakmakidis, "Active nanoplasmonic metamaterials,” Nature Materials, vol. 11, no. 7, pp. 573-584, 2012.

[2] B. Bhattarai, Y. Zaker, and T. P. Bigioni, "Green synthesis of gold and silver nanoparticles: challenges and opportunities," Current Opinion in Green and Sustainable Chemistry, vol. 12, pp. 91-100, 2018.

[3] K. Gudikandula and S. Charya Maringanti, "Synthesis of silver nanoparticles by chemical and biological methods and their antimicrobial properties," Journal of Experimental Nanoscience, vol. 11, no. 9, pp. 714-721, 2016.

[4] T. Zhang, Y.-J. Song, X.-Y. Zhang, and J.-Y. Wu, "Synthesis of silver nanostructures by multistep methods," Sensors, vol. 14, no. 4, pp. 5860-5889, 2014.

[5] B. Nowack, H. F. Krug, and M. Height, "120 years of nanosilver history: implications for policy makers," Environmental Science \& Technology, vol. 45, no. 4, pp. 1177-1183, 2011.

[6] B. Kumar, K. Smita, L. Cumbal, A. Debut, and R. N. Pathak, "Sonochemical synthesis of silver nanoparticles using starch: a comparison," Bioinorganic Chemistry and Applications, vol. 2014, Article ID 784268, 8 pages, 2014.

[7] P. Rauwel, S. Küünal, S. Ferdov, and E. Rauwel, “A review on the green synthesis of silver nanoparticles and their morphologies studied via TEM," Advances in Materials Science and Engineering, vol. 2015, Article ID 682749, 9 pages, 2015.

[8] S. Ferraris, M. Miola, A. Cochis et al., "In situ reduction of antibacterial silver ions to metallic silver nanoparticles on bioactive glasses functionalized with polyphenols," Applied Surface Science, vol. 396, pp. 461-470, 2017.

[9] H. P. Borase, B. K. Salunke, R. B. Salunkhe et al., "Plant extract: a promising biomatrix for ecofriendly, controlled synthesis of silver nanoparticles," Applied Biochemistry and Biotechnology, vol. 173, no. 1, pp. 1-29, 2014.

[10] A. Zamani, A. P. Marjani, and Z. Mousavi, "Agricultural waste biomass-assisted nanostructures: synthesis and application," Green Processing and Synthesis, vol. 8, no. 1, pp. 421-429, 2019.

[11] V. Bátori, M. Jabbari, D. Åkesson, P. R. Lennartsson, M. J. Taherzadeh, and A. Zamani, "Production of pectincellulose biofilms: a new approach for citrus waste recycling," International Journal of Polymer Science, vol. 2017, Article ID 9732329, 9 pages, 2017.

[12] B. Yang, F. Qi, J. Tan, T. Yu, and C. Qu, "Study of green synthesis of ultrasmall gold nanoparticles using citrus sinensis peel," Applied Sciences, vol. 9, no. 12, p. 2423, 2019.

[13] S. Sinha, P. Pan, P. Chanda, and S. K. Sen, "Nanoparticles fabrications using ambient biological resource," Journal of Applied Biosciences, vol. 19, pp. 1113-1130, 2009.

[14] S. Joseph and B. Mathew, "Microwave assisted biosynthesis of silver nanoparticles using the rhizome extract of alpinia galanga and evaluation of their catalytic and antimicrobial activities," Journal of Nanoparticles, vol. 2014, Article ID 967802, 9 pages, 2014.

[15] R. Bhat, R. Deshpande, S. V. Ganachari, D. S. Huh, and A. Venkataraman, "photo-irradiated biosynthesis of silver nanoparticles using edible mushroom pleurotus Florida and their antibacterial activity studies," Bioinorganic Chemistry and Applications, vol. 2011, Article ID 650979, 7 pages, 2011.

[16] D. Manikprabhu and K. Lingappa, "Microwave assisted rapid and green synthesis of silver nanoparticles using a pigment produced by streptomyces coelicolor klmp33," Bioinorganic Chemistry and Applications, vol. 2013, Article ID 341798, 5 pages, 2013. 
[17] H.-m. Kim, N. Saito, and D.-w. Kim, "Solution plasmaassisted green synthesis of $\mathrm{MnO}_{2}$ adsorbent and removal of cationic pollutant," Journal of Chemistry, vol. 2019, Article ID 7494292, 7 pages, 2019.

[18] G. Saito and T. Akiyama, "Nanomaterial synthesis using plasma generation in liquid," Journal of Nanomaterials, vol. 2015, Article ID 123696, 21 pages, 2015.

[19] A. A. Pivovarov, A. V. Kravchenko, A. P. Tishchenko et al., "Contact nonequilibrium plasma as a tool for treatment of water and aqueous solutions: theory and practice," Russian Journal of General Chemistry, vol. 85, no. 5, pp. 1339-1350, 2015.

[20] M. Skiba, A. Pivovarov, A. Makarova, O. Pasenko, A. Khlopytskyi, and V. Vorobyova, "Plasma-chemical formation of silver nanodisperssion in water solutions," Eastern-European Journal of Enterprise Technologies, vol. 6, no. 90, pp. 59-65, 2017.

[21] O. A. Pivovarov, M. I Skiba, A. K. Makarova, V. I. Vorobyova, and O. O. Pasenko, "Plasma-chemical obtaining of silver nanoparticles in the presence of sodium alginate," Voprosy Khimii i Khimicheskoi Tekhnologii, vol. 6, no. 115, pp. 82-88, 2017.

[22] M. I. Skiba, A. A. Pivovarov, A. K. Makarova, and V. I. Vorobyova, "Plasma-chemical synthesis of silver nanoparticles in the presence of citrate," Chemistry Journal of Moldova, vol. 13, no. 1, pp. 7-14, 2018.

[23] O. A. Pivovarov, M. I. Skiba, A. K. Makarova, and V. I. Vorobyova, "One-pot synthesis of silver nanoparticles using nonequilibrium low temperature plasma in the presence of polyvinyl alcohol," Voprosy Khimii $i$ Khimicheskoi Tekhnologii, vol. 3, pp. 113-120, 2018, in Russian.

[24] C. Noguez, "Surface plasmons on metal nanoparticles: the influence of shape and physical environment," The Journal of Physical Chemistry C, vol. 111, no. 10, pp. 3806-3819, 2007.

[25] M. Skiba, V. Vorobyova, A. Pivovarov, A. Shakun, E. Gnatko, and I. Trus, "“Green” synthesis of nanoparticles of precious metals: antimicrobial and catalytic properties," Eastern-European Journal of Enterprise Technologies, vol. 5, no. 6 (95), pp. 51-58, 2018.

[26] A. K. Mittal, Y. Chisti, and U. C. Banerjee, "Synthesis of metallic nanoparticles using plant extracts," Biotechnology Advances, vol. 31, no. 2, pp. 346-356, 2013.

[27] M. Skiba, A. Pivovarov, V. Vorobyova, T. Derkach, and I. Kurmakova, "Plasma-chemical formation of silver nanoparticles: the silver ions concentration effect on the particle size and their antimicrobial properties," Journal of Chemical Technology and Metallurgy, vol. 54, no. 2, pp. 311-318, 2019.

[28] M. Skiba, A. Pivovarov, A. Makarova, and V. Vorobyova, "Plasmochemical preparation of silver nanoparticles: thermodynamics and kinetics analysis of the process," EasternEuropean Journal of Enterprise Technologies, vol. 2, no. 6 (92), pp. 4-9, 2018.

[29] G. A. Martínez-Castañón, N. Niño-Martínez, F. MartínezGutierrez, J. R. Martínez-Mendoza, and F. Ruiz, "Synthesis and antibacterial activity of silver nanoparticles with different sizes," Journal of Nanoparticle Research, vol. 10, no. 8, pp. 1343-1348, 2008.

[30] M. Skiba and V. Vorobyova, "Green synthesis of silver nanoparticles using grape pomace extract prepared by plasma-chemical assisted extraction method," Molecular Crystals and Liquid Crystals, vol. 671, no. 1, pp. 142-151, 2018.

[31] I. Fernando and Y. Zhou, "Impact of $\mathrm{pH}$ on the stability, dissolution and aggregation kinetics of silver nanoparticles," Chemosphere, vol. 216, pp. 297-305, 2019.
[32] M. Vanaja, K. Paulkumar, M. Baburaja et al., "Degradation of methylene blue using biologically synthesized silver nanoparticles," Bioinorganic Chemistry and Applications, vol. 2014, Article ID 742346, 8 pages, 2014.

[33] M. Rani and U. Shanker, "Degradation of traditional and new emerging pesticides in water by nanomaterials: recent trends and future recommendations," International Journal of Environmental Science and Technology, vol. 15, no. 6, pp. 1347-1380, 2018.

[34] M. Ismail, M. I. Khan, S. B. Khan, K. Akhtar, M. A. Khan, and A. M. Asiri, "Catalytic reduction of picric acid, nitrophenols and organic azo dyes via green synthesized plant supported Ag nanoparticles," Journal of Molecular Liquids, vol. 268, pp. 87-101, 2018. 


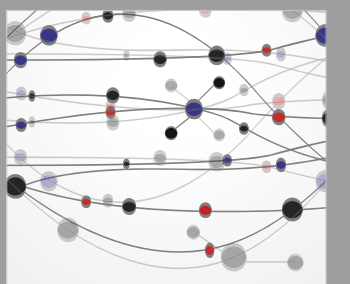

The Scientific World Journal
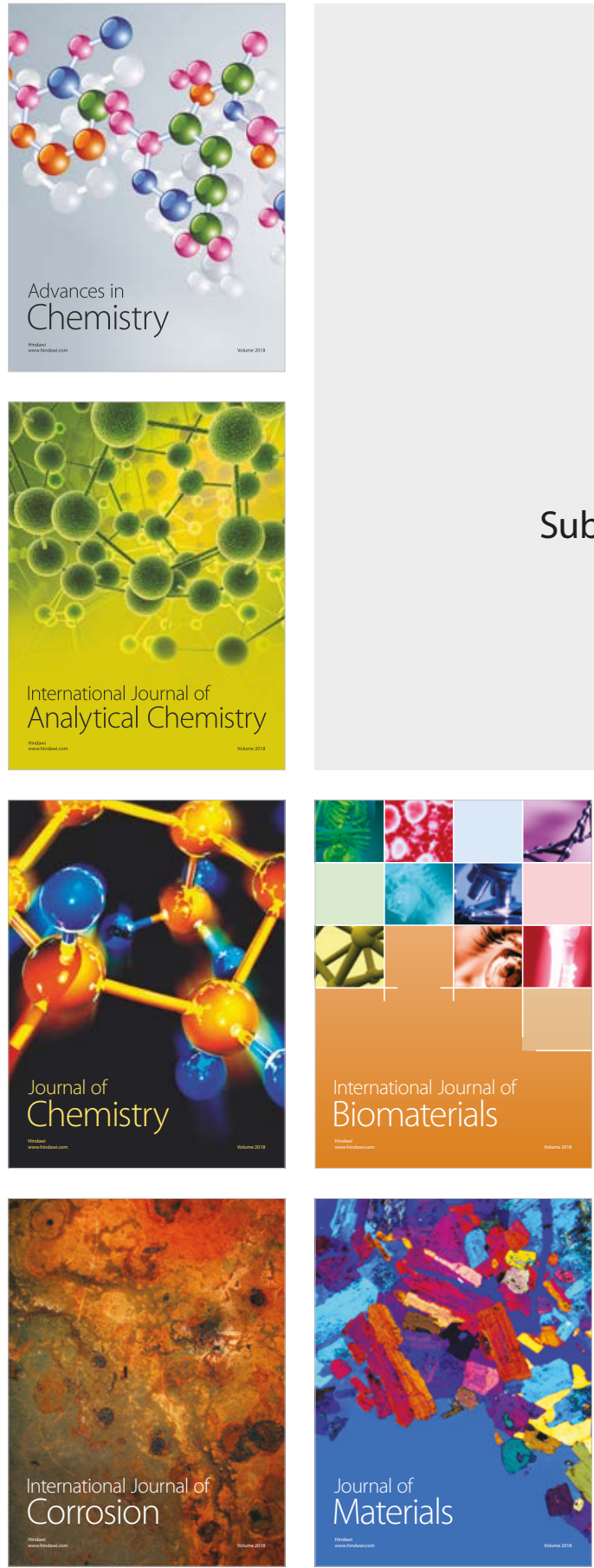

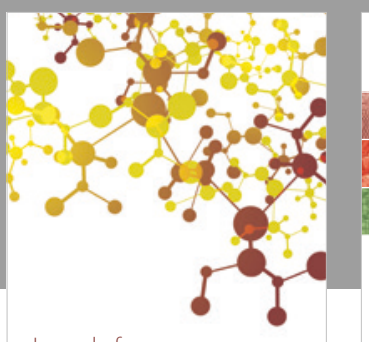

Journal of

Applied Chemistry
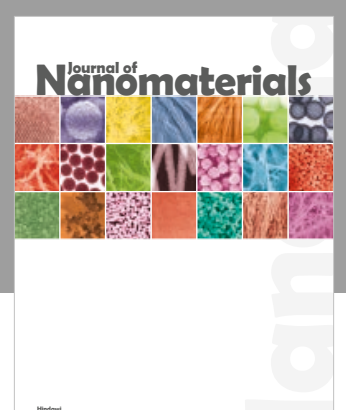

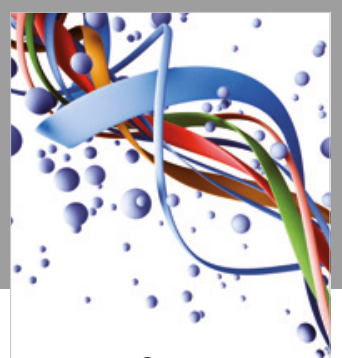

Scientifica

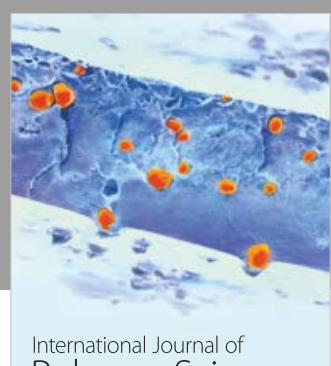

Polymer Science

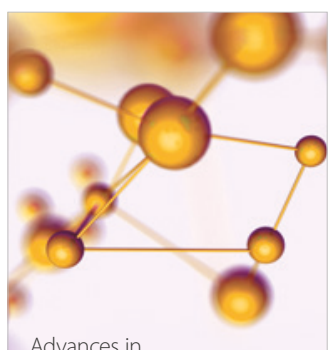

Physical Chemistry
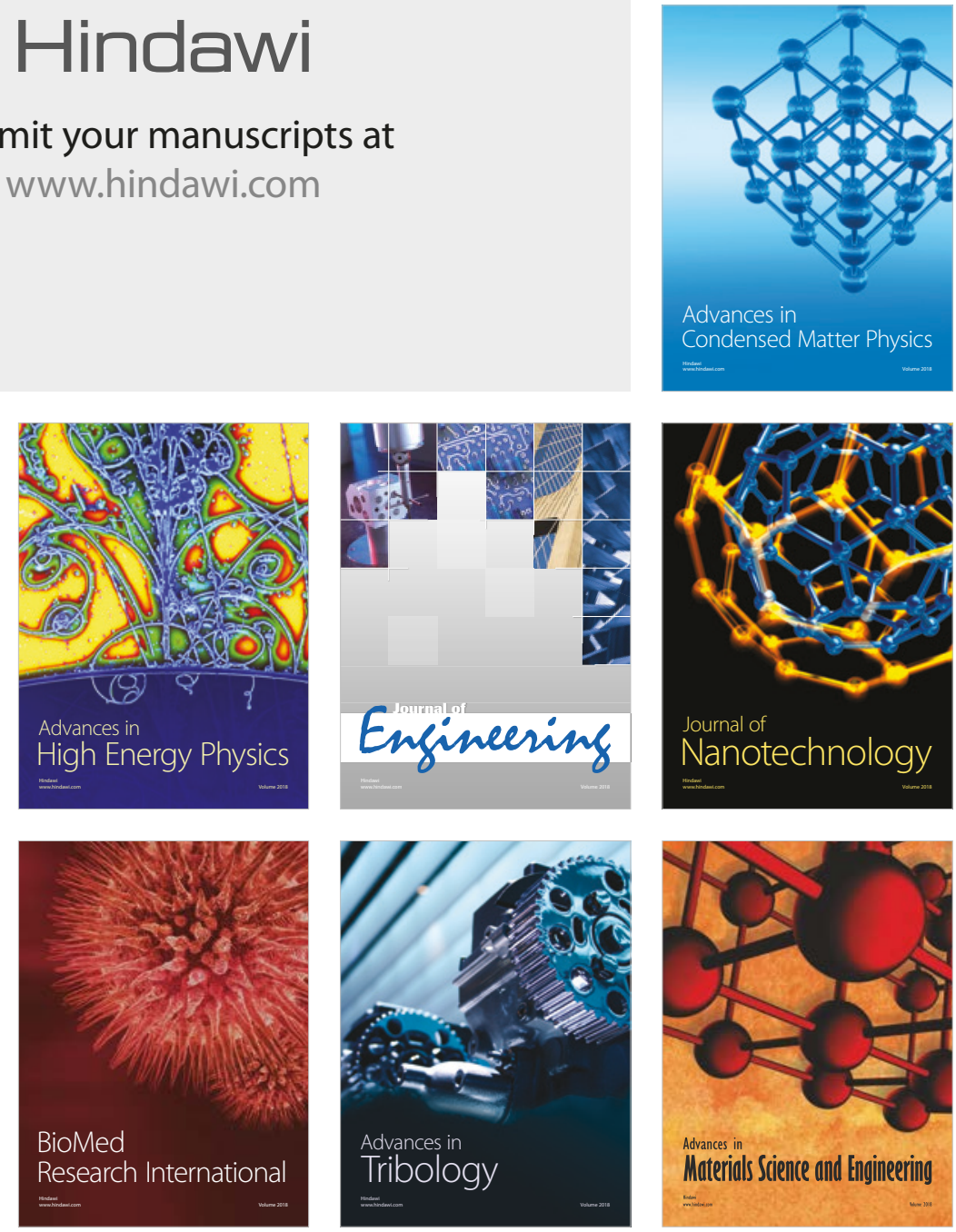